\title{
Thixotropic Properties of Latvian Illite Containing Clays
}

\author{
Vitālijs Lakevičs, Valentīna Stepanova, Santa Niedra, Inga Dušenkova, Augusts Ruplis \\ Riga Technical University
}

\begin{abstract}
Thixotropic properties of Latvian Devonian and Quaternary clays were studied. Dynamic viscosity of the water clay suspensions were measured with a rotating viscometer. Influence of concentration, pH and modifiers on the thixotropic clay properties was analyzed. It was found that Latvian clays have thixotropic properties. Stability of clay suspensions is described with the thixotropy hysteresis loop. Increasing the speed of the viscometer rotation, dynamic viscosity of the clay suspension decreases. It was found that the solid phase concentration and mineralogical composition make an impact on the thixotropy of clays. Decreasing the solid phase concentration in the clay suspensions from $50 \%$ to $25 \%$, dynamic viscosity decreases proportionally to the solid phase concentration.

It was found that modifying clay suspensions with carboxymethyl cellulose $(0,1 \mathrm{~g})$ increases concentration of structure forming. In the same time, modifying of clay suspensions with calcified soda $(0,1 \mathrm{~g})$ decreases the structure forming concentration. Dependence of $\mathrm{pH}$ value from the solid phase concentration slightly decreases with the clay phase concentration increasing in the suspension.
\end{abstract}

Key words: thixotropy, viscosity, clay, suspension, solid phase.

\section{INTRODUCTION}

Studying thixotropic properties could clear the way to a perspective and vital chance to use Latvian clays in the powdered compositions which are used as sorbents for collection of leaked oil and oil products from water aquatoriums or like components of drilling solutions. Thanks to thixotropy, clays can be used even in medicine or cosmetics that nowadays are trying to create innovative products from natural materials. Thixotropic properties of Latvian clays are not yet completely investigated. Thixotropy is the phenomenon of the fluid which shows a reversible structural transition (i.e., gel-sol-gel conversion) due to the timedependent changes in the viscosity induced by temperature, $\mathrm{pH}$ or other components without any changes in the volume of the system [1-3]. According to the IUPAC terminology, thixotropy is defined as the continuous decrease of viscosity with time, when flow is applied to a sample that has been previously at rest and the subsequent recovery of viscosity in time when the flow is discontinued. There are three essential elements of the thixotropy definition used nowadays: it is based on viscosity; it implies a time-dependent decrease of the viscosity induced by flow; the effect is reversible when the flow is decreased or arrested [2].

In other words, thixotropy is a term to describe an isothermal system in which the apparent viscosity decreases under shear stress, followed by a gradual recovery when the stress is removed [1]. Systems that correspond to a definition of thixotropy, have various rheological parameters. Quantitative determination of thixotropy is a sophisticated process, since measuring of rheological functions is complicated. Since the system is heterogenic, it is often not easy to take measurements, because particles may sink or stick to the walls. Under the impact of microstructure variation, other physical, optical and dielectric properties may also change. There are many methods of thixotropy determination, but the most suitable way for the measurement of thixotropy is to describe the material response in shear stress due to an inflicted deformation or a shear rate [1-3]. Thixotropic properties depend on microstructure of the system, ability of particles to form agglomerates of various sizes under impact of mutual interaction. Also, thixotropy is impacted by concentration, particle sizes, system $\mathrm{pH}$ value, temperature, presence of anions and cations, sample concentration and other factors. If the solid phase contains polar particles, then structure forming in suspension occurs also at comparatively low concentrations, for example, a smectyte concentration of $1 \%$ is sufficient to demonstrate thixotropic properties, for smectyte clays form three-dimensional ("cardhouse") structure and suspension can coagulate. Apparent viscosity increases exponentially with the clay concentration. If a suspension contains a high solid phase concentration, and the particles sedimentate, then the structure is not forming. [4-6].

Thixotropy is a very widely spread phenomenon in various fields of industry and natural systems. Industry applications involve mineral and metal processing, manufacturing of foods, pharmaceuticals, cosmetics. We see it every day when we use products like tooth paste, shampoo, lotion, coatings, dyes, gels and tints [78]. By modifying natural Latvian clays, one may achieve desired surface and thixotropy properties, that give possibility to use them for processing waste waters or vegetable oils or in many other industries. [9].

In the present research, the typical hysteresis loop rheology test method was employed to evaluate thixotropy of various Latvian illite containing clays. Influence of concentration, $\mathrm{pH}$ and modifiers on the thixotropic clay properties was analyzed. 


\section{MATERIALS AND METHODS}

Research objects and preparation for thixotropic experiments

Objects of this research are Latvia originated Devonian (Pavāri, Planči, Skaņkalne) and quaternary (Ceplīši, Prometejs, Ugāle) deposits of illite clays.

Granulometric composition of the analyzed samples was determined using the particle size analyzer "Analyzette 22 NanoTech"(Fritch, Germany). Mineralogical composition of clay samples was analyzed by X-ray powder diffraction (XRD) (X'Pert Pro, Philips, The Netherlands). Description of the researched clay samples is given in Table 1 and Fig.1.

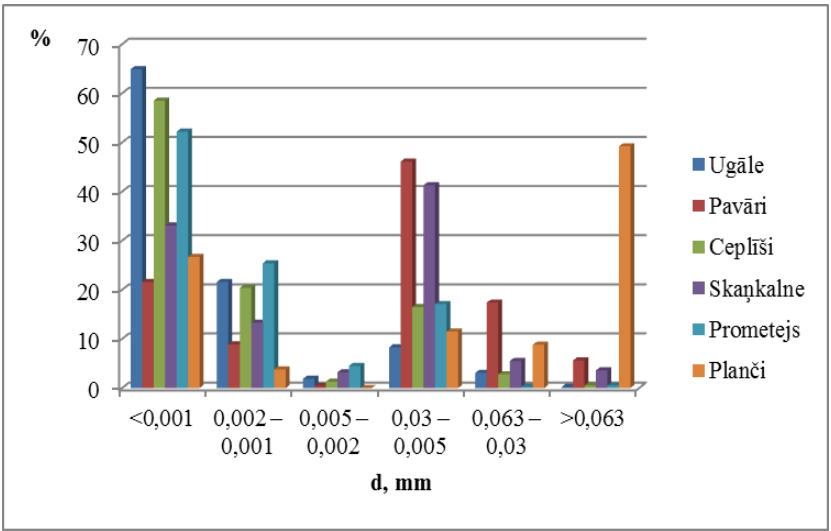

Fig.1. Granulometric composition of the analyzed clay samples.

1.TABLE

MINERALOGICAL COMPOSITION OF ANALYZED LATVIAN CLAY SAMPLES

\begin{tabular}{|l|l|l|l|l|}
\hline \multirow{2}{*}{$\begin{array}{l}\text { Mineral } \\
\text { content } \%\end{array}$} & \multicolumn{4}{|l}{ Clay sample } \\
\cline { 2 - 5 } & Pavāri & Prometejs & Skaņkalne & Ugāle \\
\hline quartz & 53,89 & 12,65 & 42,59 & 9,92 \\
\hline illite & 34,54 & 42,98 & 37,16 & 36,46 \\
\hline kaolinite & 3,94 & 2,93 & 9,53 & 1,89 \\
\hline goethite & - & 2,64 & 4,79 & 1,02 \\
\hline orthoclase & - & 17,01 & 5,94 & 5,38 \\
\hline albite & 7,64 & - & - & 5,51 \\
\hline chlorite & - & 4,61 & - & 13,9 \\
\hline calcite & - & 8,39 & - & 7,97 \\
\hline dolomite & - & 8,17 & - & 4,48 \\
\hline muscovite & - & 0,22 & - & - \\
\hline haematite & - & 0,4 & - & - \\
\hline
\end{tabular}

Determining volume of humidity in the analyzed clay samples

In order to determine clay sample humidity composition, a sample of $1 \mathrm{~g}$ mass is placed in a porcelain pot which was previously dried at $105^{\circ} \mathrm{C}$ temperature up to a constant weight. The clay sample containing pot is dried at $110^{\circ} \mathrm{C}$ temperature up to a constant weight. The obtained results are summarized in Table 2.

Humidity volume (W\%) is calculated using the following equation:

$$
W \%=\frac{\left(m_{1}-m_{2}\right)}{m} \cdot 100
$$

where $\mathrm{m}_{1}$ - clay mass with the pot before drying, $\mathrm{g}$; $\mathrm{m}_{2}$ - clay mass with the pot after drying, $\mathrm{g}$; $\mathrm{m}-$ clay mass, $\mathrm{g}$.

. TABLE 2

VOLUME OF HUMIDITY OF LATVIAN CLAY SAMPLES

\begin{tabular}{|l|l|l|l|}
\hline Clay deposit & Period & $\begin{array}{l}\text { Layer } \\
\text { thickness of } \\
\text { taken } \\
\text { samples (m) }\end{array}$ & Humidity \% \\
\hline Cepl̄̄̌si & Quaternary & $2,2-3,0$ & 24,0 \\
\hline Pavāri & Devonian & $1,8-2,3$ & 16,6 \\
\hline Planči & Devonian & $1,5-2,2$ & 19,9 \\
\hline Prometejs & Quaternary & $1,5-2,0$ & 20,1 \\
\hline Skaņkalne & Devonian & $2,0-3,0$ & 19,0 \\
\hline Ugāle & Quaternary & $1,5-3,0$ & 31,0 \\
\hline
\end{tabular}

Clay suspensions were prepared from the studied clay samples which are mechanically cleared from additions, crashed in a pestle, dispersed and swollen in a distilled $\mathrm{H}_{2} \mathrm{O}$ for 1 month. Swollen clays in suspension form are sieved and dried in $105^{\circ} \mathrm{C}$ temperature, by that obtaining a fine clay-aleirite fraction with particle size < $63 \mu \mathrm{m}$.

Dry samples, $250 \mathrm{~g}$ each, were crushed in a mortar, added to $250 \mathrm{~g}$ of distilled water and the prepared $50 \%$ clay suspensions were matured for 1 months in order to ensure replicability and invariability.

\section{Density measurements}

$10 \mathrm{ml}$ of suspension sample was weighted on the analytical scales and its density was calculated using the following equation:

$$
\rho_{s}=\frac{m_{s}}{V_{s}}
$$

where $\rho_{\mathrm{s}}$ - solution density, $\mathrm{g} / \mathrm{ml}$;

$\mathrm{m}_{\mathrm{s}}$ - fluid mass, $\mathrm{g}$;

$\mathrm{V}_{\mathrm{s}}$ - fluid volume, $\mathrm{ml}$

\section{Viscosity measurements}

For viscosity measurements rotational viscometer Fungilab EXPR 300002 (Spain) was used. For measuring viscosity, sample suspension in a $600 \mathrm{ml}$ glass is taken. 5 minutes before measuring suspensions were mechanically activated, mixed with a mechanical mixer, in order to increase clay sample dispersity and ability to respond. One of the viscosity measuring 
spindles is chosen. Suspension density value is inserted, required time and regime of measurements is set rotation speed gradual variation interval (RAMP) which may vary in the range from $0.01-200$ rotations per minute or multistep program with set speeds of spindle rotation.

\section{Thixotropy measurements}

The hysteresis loop rheology test method was employed to evaluate thixotropy of various Latvian illite containing clays.

Viscosity measurements are taken using a rotation viscosimeter MULTISTEP program. Measurement points are set in an available thixotropy interval, increasing in the beginning (until the chosen maximum) and then the reducing rotation speed sequence. Obtained dynamic viscosity data is processed, calculating the angular speed:

$$
\omega=2 \pi / 60 \cdot N
$$

where $\omega-$ angular velocity of spindle, $\mathrm{rad} / \mathrm{sec}$;

$$
\mathrm{N} \text { - spindle RPM. }
$$

For calculating shear stress and shear rate formula (4) and (5) were used:

$$
\dot{\gamma}=\frac{2 \omega R_{C}^{2} R_{b}^{2}}{R_{b} 2\left(R_{C}^{2}-R_{b}^{2}\right)},
$$

where $\dot{\gamma}$ - shear rate, $\sec ^{-1}$;

$\omega$ - angular velocity of spindle, $\mathrm{rad} / \mathrm{sec}$;

$\mathrm{R}_{\mathrm{c}}$ - radius of container, $\mathrm{cm}$;

$\mathrm{R}_{\mathrm{b}}$ - radius of spindle, $\mathrm{cm}$.

$$
\tau_{w}=\frac{M}{2 \pi R_{b}^{2} L},
$$

$\operatorname{kur} \tau_{w}-$ shear stress, dyn $/ \mathrm{cm}^{2}$

$\mathrm{M}$ - Torque acting on surface of spindle, $\mathrm{N} \cdot \mathrm{m}$ (instrument reading);

$\mathrm{R}_{\mathrm{c}}$ - radius of container, $\mathrm{cm}$;

$\mathrm{R}_{\mathrm{b}}$ - radius of spindle, $\mathrm{cm}$;

$\mathrm{L}-$ effective spindle side length, $\mathrm{cm}$

\section{RESULTS AND DISCUSSION}

\section{Viscosity of clay suspensions}

Figure 2 shows variation of dynamic viscosity depending in the sample's solid phase concentration mass share $\mathrm{w} \%$, at rotation speed $10 \mathrm{rpm}$. Viscosities of clay sample suspensions significantly differ in between. It can be explained by their different composition and construction. It can be observed that the Planči deposit samples demonstrate the highest viscosity, followed by Ugāle and Prometejs deposit samples since the samples not only contain clay minerals, but also aleirite fractions, viscosity may also be impacted by dolomite contained in the samples. All the samples demonstrate reduction of viscosity with reduction of solid phase, which can be explained by quartz contained in the samples, which quickly sinks in the diluted suspensions and does not form any structures.

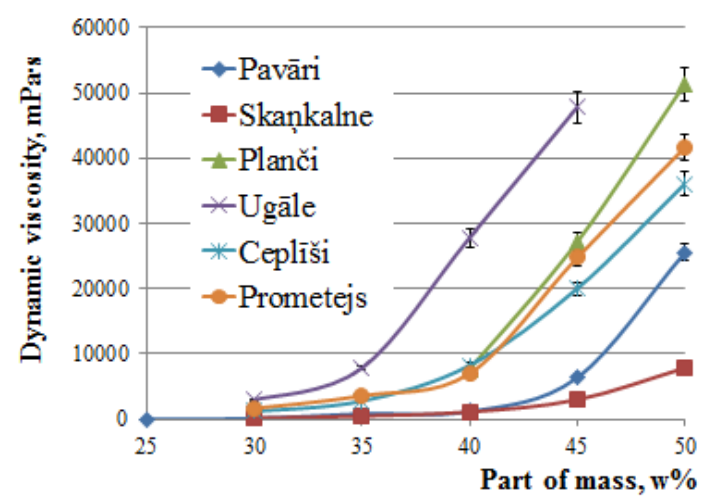

Fig.2. Dynamic viscosity of clay suspensions depending on solid phase concentration

\section{Thixotropy of clay suspensions}

In order to determine if a material has any thixotropic properties, viscosity is measured using multistep program. The data obtained was processed and shear rate and shear stress were calculated using formulas (4) and (5). The results were showed on figures, plotting shear rate on the abscissa and shear stress on the ordinate. If a hysteresis loop is formed, it shows a thixotropy. If no hysteresis loop is formed, it means that this material has no thixotropic properties.

Almost all the analyzed samples have thixotropic properties with only solid phase concentration varies where they are more pronounced. Comparing thixotropic properties of all the samples with a similar concentration as it is shown on figure 3 , it is characteristic to all the samples. More distinct thixotropic properties at $30 \%$ solid phase concentration are demonstrated by samples from Ceplīši and Prometejs deposits. Hysteresis loops do not correspond to a theoretical shape, but since the suspensions also contain aleirite which makes their structure uneven, and other clay minerals, these hysteresis loops are considered as proof of thixotropy. Analyzing each of the samples separately, in a certain interval, hysteresis loops are closer to the expected shape. 


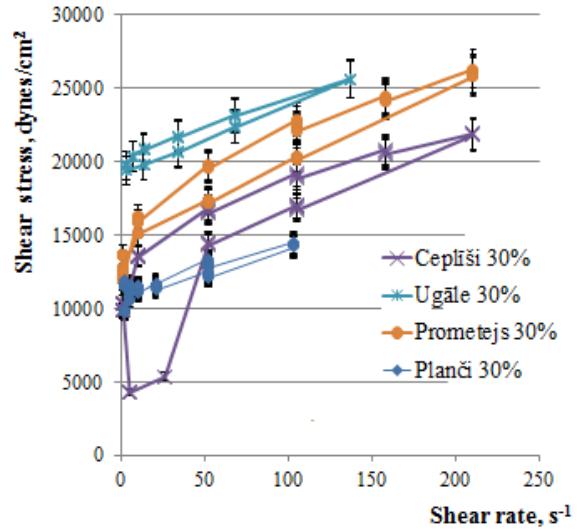

Fig.3. Hysteresis loops of $30 \%$ clay-water suspensions

With solid phase concentration changing in the suspension, thixotropic properties change as well. In the much diluted suspensions, particle sedimentation is observed and their mutual attracting powers are not so distinct. In the concentrated suspensions, gaps between particles are too small and it causes particle repulsion. (see Fig.4).

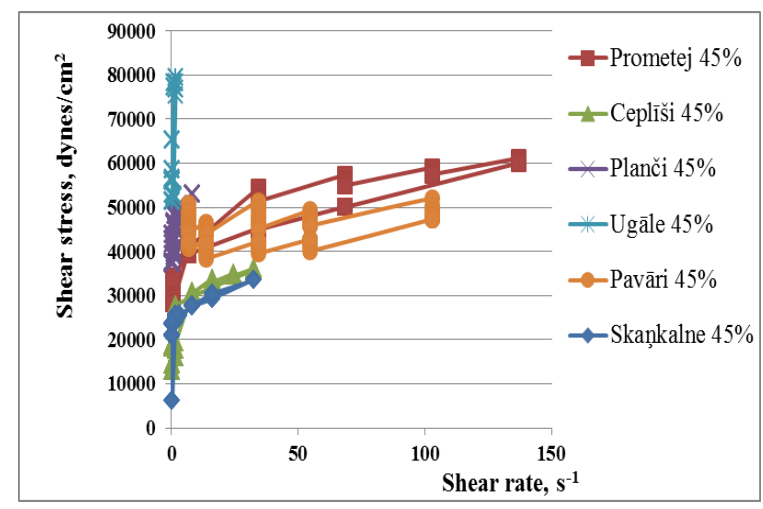

Fig.4. Hysteresis loops of $45 \%$ clay-water suspensions

As the Fig. 4 shows, thixotropic properties of a $45 \%$ suspension differ from those of $30 \%$ suspension. A high content of solid phase gives a possibility that non-polar particles might sedimentate in the lowest part of measuring cylinder.

\section{pH influence on clay thixotropy}

The analyzed clay suspensions have various compositions and properties. They are also different by $\mathrm{pH}$ value and electric conductivity. The output values of $\mathrm{pH}$ and electric conductivity values of the $50 \%$ suspension are shown in Table 3.

TABLE 3

PHYSICAL PROPERTIES OF THE ANALYZED CLAY SUSPENSIONS

\begin{tabular}{|l|l|l|l|l|}
\hline Sample & $\mathrm{pH}$ & $\mathrm{E}_{\mathrm{o}}, \mathrm{mV}$ & $\mathrm{T},{ }^{\circ} \mathrm{C}$ & $\rho, \mathrm{g} / \mathrm{ml}$ \\
\hline Ceplīši $50 \%$ & 7,34 & $-47,2$ & 21,6 & 1,458 \\
\hline Skaṇkalne 50\% & 4,79 & 100,7 & 23,4 & 1,485 \\
\hline Pavāri 50\% & 5,2 & 40,9 & 21,5 & 1,421 \\
\hline
\end{tabular}

\begin{tabular}{|l|l|l|l|l|}
\hline Planči 50\% & 6,65 & $-9,2$ & 22,4 & 1,479 \\
\hline Prometejs 50\% & 7,14 & $-38,7$ & 21,8 & 1,246 \\
\hline Ugāle 50\% & 7,19 & $-47,1$ & 23,2 & 1,436 \\
\hline
\end{tabular}

With changing the solid phase concentration, clay suspension physical properties also change. At every sample these changes are different, however a general tendency is observed that with solid phase concentration reduction, the $\mathrm{pH}$ value increases and the density decreases (see Table 4). With solid phase concentration change, clay suspension physical properties are also changed. These changes are different at every sample, however a general trend is observed - with solid phase concentration reduction, $\mathrm{pH}$ value increases and density is reduced (see Table 4). It therefore impacts viscosity and thixotropy, for with density reduction, dynamic suspension viscosity decreases as well.

TABLE 4

PHYSICAL SAMPLE PROPERTIES DEPENDING ON CLAY MASS SHARE COMPOSITION

\begin{tabular}{|l|l|l|l|l|l|}
\hline \multirow{2}{*}{$\begin{array}{l}\text { Physical } \\
\text { properties of the } \\
\text { sample }\end{array}$} & \multicolumn{5}{|l}{ Clay mass share, \% } \\
\cline { 2 - 6 } & $50 \%$ & $45 \%$ & $40 \%$ & $35 \%$ & $30 \%$ \\
\hline Skaṇkalne, pH & 4,79 & 4,88 & 4,85 & 4,98 & 4,92 \\
\hline $\begin{array}{l}\text { Skaņkalne, } \rho, \\
\text { g/ml }\end{array}$ & 1,49 & 1,42 & 1,36 & 1,35 & 1,33 \\
\hline Pavāri, pH & 5,20 & 5,95 & 6,10 & 6,38 & 6,40 \\
\hline Pavāri, $\rho, g / m l$ & 1,42 & 1,41 & 1,41 & 1,40 & 1,26 \\
\hline Ugāle, pH & 7,19 & 7,30 & 7,37 & 7,52 & 7,66 \\
\hline Ugāle, $\rho, g / m l$ & 1,44 & 1,42 & 1,39 & 1,30 & 1,28 \\
\hline Planči, pH & 6,65 & 6,19 & 6,52 & 6,13 & 6,39 \\
\hline Planči, $\rho, g / m l$ & 1,48 & 1,48 & 1,48 & 1,39 & 1,27 \\
\hline
\end{tabular}

Modifier impact on clay - water suspensions stability and thixotropy

Modifiers - sodium carbonate $\left(\mathrm{Na}_{2} \mathrm{CO}_{3}\right)$ and carboxymethyl cellulose sodium chloride (KMC) impact both physical properties of the suspension and viscosity and thixotropy. $0.1 \mathrm{~g}$ of additives for $200 \mathrm{ml}$ of suspension were added to $30 \%$ of Skaņkalne, Planči and Ugāle deposit samples. A general trend is observed at all the samples - after processing with soda-ash, viscosity reduces and the structure forming concentration lowers. It is explained by the contents of carbonates in the samples that react with the soda and sedimentate as $\mathrm{CaCO}_{3}$. With adding $\mathrm{KMC}$, viscosity increases, suspension becomes more stable and structure forming concentration increases. Comparison of dynamic viscosity of the non-modified and modified samples is demonstrated on Figure 5.

Adding modifiers impact clay thixotropic properties and change suspension structure. Adding the $\mathrm{Na}_{2} \mathrm{CO}_{3}$ negatively impacts the thixotropy, hysteresis loops are not formed or gaps between them are very small. Adding KMC improves the thixotropic properties, hysteresis loop is formed with a wider area, and 
thixotropic properties are demonstrated after a short period of time - when the suspension is no longer mechanically influenced, it quickly restores its viscosity (see Fig.6).

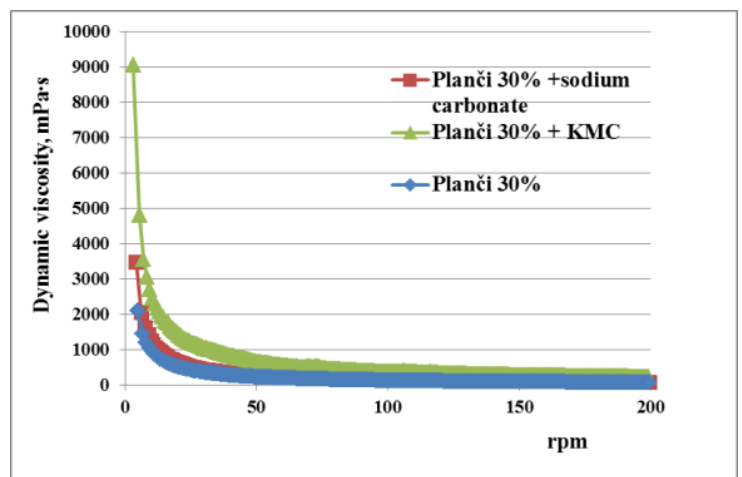

Fig.5. Dynamic viscosity of Planči deposit clay water suspension depending on added modifier

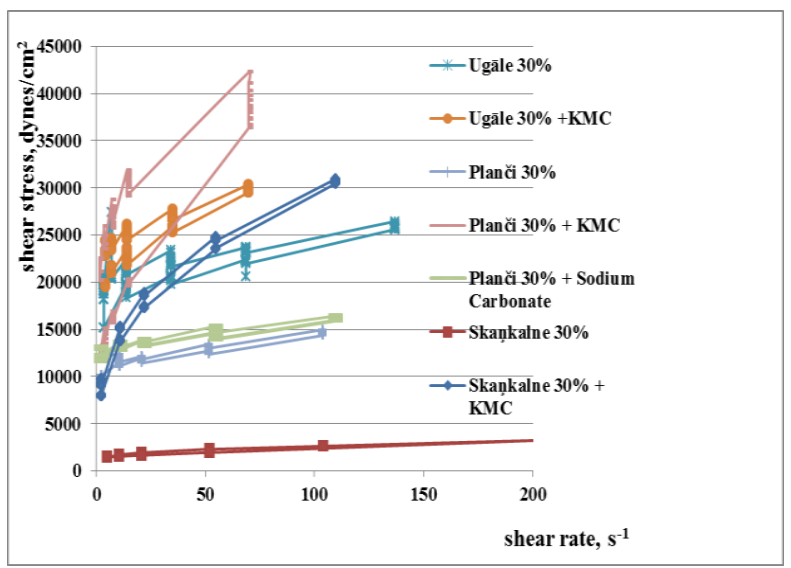

Fig.6. Thixotropy of Latvian clays depending on added modifier

Fig.6.shows how adding KMC stabilizes the clay suspension; hysteresis loop is significantly wider than the hysteresis loop of a non-modified clay suspension.

\section{CONCLUSIONS}

It was found that Latvian clays have thixotropic properties.

Clay suspension stability is described by the thixotropy hysteresis loop.

Increasing the speed of the viscometer rotation, dynamic viscosity of the clay suspension decreases.

Solid phase concentration and mineralogical composition make an influence on the thixotropy.

Decreasing the solid phase concentration in the suspensions from $50 \%$ to $25 \%$, dynamic viscosity decreases proportionally to the solid phase concentration.

It was found that modifying of clay suspensions with carboxymethyl cellulose $(0,1 \mathrm{~g})$ increases concentration of structure forming. In the same time, modifying of clay suspensions with the sodium carbonate $(0,1 \mathrm{~g})$ lowers the structure forming concentration.
Dependence of $\mathrm{pH}$ value from the solid phase concentration slightly decreases with the clay phase concentration increasing in the suspension.

\section{REFERENCES}

[1] C.H.Lee, V.Moturi, Y.Lee. Thixotropic property in pharmaceutical formulations. J. Controlled Release, 2009, 136 , pp. $88-98$.

[2] J.Mewis, N.J.Wagner. Thixotropy. Adv. Colloid Interface Sci., 2009, (147-148), 214-227.

[3] Y.Li, W.Hou, W.Zhu. Thixotropic properties of aqueous suspensions containing cationic starch and aluminum magnesium hydrotalcite-like compound. J. Colloid Interface Sci., 1, 2007, 313, pp.305-314.

[4] C.Zhu, J.E.Smay. Thixotropic rheology of concentrated alumina colloidal gels for solid freeform fabrication. J. Rheol., 2011, 55, pp.655-673.

[5] B.Derakhshandeh, D.Vlassopoulos, S.Hatzikiriakos. Thixotropy, yielding and ultrasonic doppler velocimetry in pulp fibre suspensions. Rheol. Acta, 2011, pp. 1-14.

[6] A.Malkin, S.Ilyin, A.Semakov, V.Kulichikhin. Viscoplasticity and stratified flow of colloid suspensions. Soft Matter, 2012, 8 , 2607-2617.

[7] M.I.Carretero, M.Pozo. Clay and non-clay minerals in the pharmaceutical and cosmetic industries Part II. Active ingredients. Appl. Clay Sci., 3, 2010, 47(3-4), pp.171-181.

[8] C.Viseras, C.Aguzzi, P.Cerezo, A.Lopez-Galindo. Uses of clay minerals in semisolid health care and therapeutic products. Appl. Clay Sci., 2007, 36(1-3), pp. 37-50.

[9] A.Ruplis. Sorption and catalytic properties of Latvian clay powders. Progress in Colloid and Polymer Science; SpringerVerlag 2000, 116, pp. 48-56. 